\title{
INTEGRATING SUSTAINABILITY AND MANUFACTURING STRATEGY IN A UNIFIED FRAMEWORK
}

\begin{abstract}
The direction of current literature in addressing sustainability issues in the manufacturing sector highlights some models and approaches that are usually based on the concept of the triple-bottom line. However, as a functional unit, the role of the manufacturing function in promoting competitiveness has been surpassed by the current demands of sustainability such that desired integration has been difficult to attain. This paper proposes a unifying framework in formulating a manufacturing strategy which espouses sustainability with due consideration of the manufacturing internal and external competitive functions. The proposed framework integrates the features based on the classical theories of manufacturing strategy and the other features that must be considered to transform it into a sustainable manufacturing strategy. This framework serves as a guide for decision-makers in identifying policies in various manufacturing decision areas that would comprise a sustainable manufacturing strategy. Multicriteria decision-making (MCDM) approaches were found to be relevant and appropriate due to the complexity of the strategy formulation problem brought about by the subjectivity, interdependencies of decision components and vagueness in decision-making. A probabilistic fuzzy analytic network process (PROFUZANP), which was proposed by Ocampo and Clark, was adopted to identify the content of the strategy. Results of recent empirical studies that are based on the models generated from the framework are presented in this paper.
\end{abstract}

Keywords: manufacturing, sustainability, multi-criteria decision-making, analytic hierarchy process, analytic network process

\section{Introduction}

The move towards higher degree of sustainable manufacturing is a field of interest of industry and society. This study intends to understand the forces at play in developing a sustainable manufacturing strategy, that is, how it depends on the competitive priority that the firm adopts in the presence of stakeholders' interests. It is important considering the conflicting interests of stakeholders despite the urgency imposed on industry by sustainable advocates within and outside its boundaries.

\section{Literature Review}

Sustainable manufacturing forwards the development of products and processes that promote environmental stewardship, economic growth and social well-being simultaneously, widely known as triple-bottom line. The framework of this study 
was inspired by Skinner (1969) who provided the hierarchical top-down framework relating corporate, business and manufacturing strategies. It also explored the impact of stakeholders' concerns for the environment in the manufacturing strategy formulation process considering the work of Johansson and Winroth (2010). The intent is to develop the content of a manufacturing strategy, incorporating influencing issues such as firm's competitive strategy within the context of various stakeholders' interests. Analytic Hierarchy Process (AHP) / Analytic Network Process (ANP), developed by Saaty (1980), is a general theory of relative measurement used to derive priority scales from paired comparisons of elements. In order to handle uncertainty in the decision-making, linguistic terms were utilized to elicit judgment in the form of triangular fuzzy number (Tseng, 2009). In aggregating responses, many researchers used the triangular probability distribution of respondents' judgment, which was further extended to group decision-making by introducing probability distribution on a range of individual judgment. Ocampo and Clark (2014) adopted PROFUZANP which aggregated judgment from a normal distribution.

\section{Hypotheses/Objectives}

The general objective of this work is to provide guidelines for decision-makers in the development of a sustainable manufacturing strategy. Specifically, it intends to explore the influences of different stakeholders' interests on the strategic orientation of the firms toward sustainability within a unified framework that integrates the concepts of sustainable manufacturing and manufacturing strategy.

\section{Research Design/Methodology}

This study is a two-phase process: the development of the model for sustainable manufacturing and elicitation of responses to a paired-comparison questionnaire based on the model. The decision components and elements were obtained from extensive literature review in sustainability and manufacturing strategy fields. The model was refined based on the evaluation of experts. Questionnaires were forwarded to ten identified experts in the field. They were given a maximum of four weeks to answer the questionnaire. Judgment consistency was checked throughout the pairwise comparison matrices, using the computed Consistency Index (CI) and Consistency Ratio (CR). Acceptable CR values must be less than 0.1. Decision-makers were given another two weeks to repeat the pairwise comparisons for CR values greater than 0.1 .

Aggregation of experts' judgements was carried out by introducing a normal probability distribution in each paired comparison with mean equal to the geometric mean of the judgments and standard deviation equal to a predefined perturbation about the mean. 


\section{Data/Model Analysis}

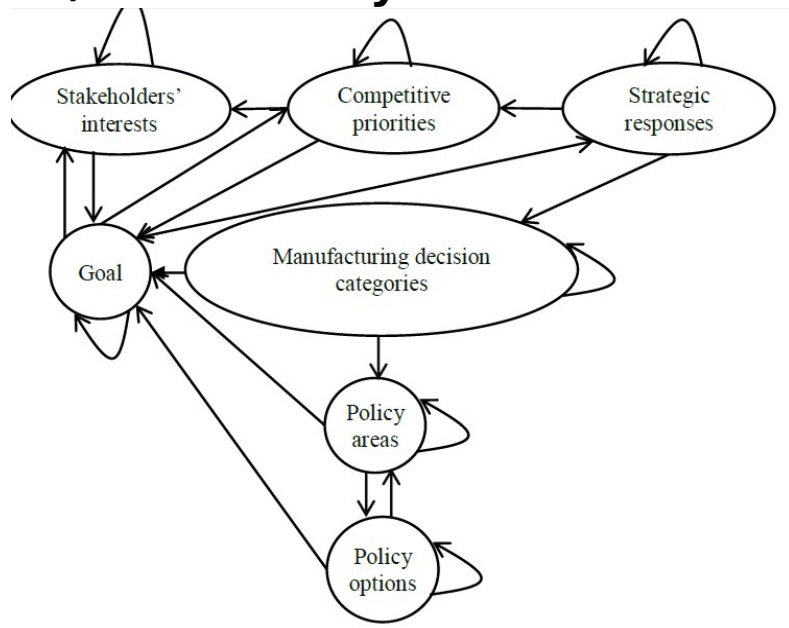

Figure 1: A digraph on manufacturing strategy with competitive priorities motivated by different stakeholders

Table 1: A sample of limiting pairwise comparisons matrix

\begin{tabular}{|c|c|c|c|c|c|c|c|c|}
\hline & 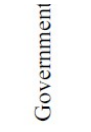 & $\frac{\stackrel{n}{\frac{D}{n}}}{\frac{\bar{a}}{\bar{\Xi}}}$ & $\begin{array}{l}\frac{\overline{0}}{0} \\
\frac{0}{0} \\
\frac{\pi}{0} \\
\frac{\pi}{\pi} \\
\frac{\pi}{n}\end{array}$ & 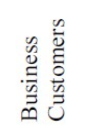 & 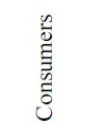 & 哭 & 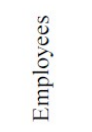 & 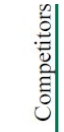 \\
\hline Government & 0.07185 & 0.07185 & 0.07185 & 0.07185 & 0.07185 & 0.07185 & 0.07185 & 0.07 \\
\hline Suppliers & 0.14433 & 0.14433 & 0.14433 & 0.14433 & 0.14433 & 0.14433 & 0.14433 & 0.144 \\
\hline Shareholders & 0.22397 & 0.22397 & 0.22397 & 0.22397 & 0.22397 & 0.22397 & 0.22397 & 0.223 \\
\hline Business customers & 0.19541 & 0.19541 & 0.19541 & 0.19541 & 0.19541 & 0.19541 & 0.19541 & 0.195 \\
\hline Consumers & 0.14954 & 0.14954 & 0.14954 & 0.14954 & 0.14954 & 0.14954 & 0.14954 & 0.149 \\
\hline Community & 0.07137 & 0.07137 & 0.07137 & 0.07137 & 0.07137 & 0.07137 & 0.07137 & 0.071 \\
\hline Employees & 0.08763 & 0.08763 & 0.08763 & 0.08763 & 0.08763 & 0.08763 & 0.08763 & 0.087 \\
\hline Competitors & 0.05590 & 0.05590 & 0.05590 & 0.05590 & 0.05590 & 0.05590 & 0.05590 & 0.05 \\
\hline
\end{tabular}

Table 2: Priority ranking of stakeholders

\begin{tabular}{lllcc}
\hline 1 & H4 & business customers & & \multicolumn{2}{c}{ Table 3: Ranking of competitive priorities } \\
2 & H3 & Shareholders & Il & Cost \\
3 & H2 & Suppliers & I2 & quality \\
4 & H5 & Consumers & It & flexibility \\
5 & H7 & Employees & I4 &
\end{tabular}




\begin{tabular}{llll} 
ode & Policy area & Code & Highest priority policy choice \\
\hline 11 & process choice & C112 & batch \\
12 & technology & C122 & flexible manufacturing system \\
13 & process integration & C132 & process \\
21 & facility size & C211 & one big plant \\
22 & facility location & C221 & close to market \\
23 & facility focus & C231 & product groups \\
31 & capacity amount & C312 & based on inputs \\
32 & capacity timing & C321 & leading \\
33 & capacity type & C333 & effective \\
11 & direction & C411 & forward \\
12 & extent & C421 & sources of raw materials \\
13 & balance & C432 & medium degree \\
i1 & structure & C511 & functional \\
i2 & reporting levels & C522 & middle \\
i3 & support groups & C532 & small groups \\
51 & system design & C611 & make-to-order \\
52 & decision support & C621 & close support \\
53 & systems integration & C631 & high degree \\
71 & defect prevention & C711 & high quality \\
72 & monitoring & C721 & high frequency \\
73 & intervention & C731 & high frequency \\
31 & rate of innovation & C812 & fast \\
32 & product design & C821 & standard \\
33 & industrialization & C831 & new processes \\
11 & skill level & C911 & specialized \\
12 & pay & C922 & quantity/quality of output \\
33 & security & C931 & training \\
& & &
\end{tabular}

Also a result of the study is a table of the priority ranking of stakeholders' interests.

\section{Conclusions}

In this study, business customers (H4) emerge as the first priority rank of stakeholders' component followed by shareholders. This could be explained by the scenario that while the government is inclined to impose regulatory stances on the firm, customers, shareholders and suppliers can perform collaborative work toward a sustainable supply chain.

Cost has the highest priority in the competitive priorities component followed by quality, flexibility and dependability. Process technology decision area ranked first in the manufacturing strategy decision category and closely followed by capacity.

In each of the manufacturing decision category, priority policy areas are also identified. These prioritized policy areas are: technology in process technology decision, facility location in facilities decision, capacity timing in capacity decision, direction in vertical integration decision, structure in organization decision, system design in manufacturing planning and control decision, defect prevention in quality decision, rate of innovation in new product introduction, and skill level in human resources decision.

It is shown that the top six stakeholders' interests include government's increased taxes, community's employment, governments and community's health and safety. These confirm that the motivation towards a more sustainable manufacturing came from stakeholders socio-environmental interests. 


\section{Key References}

Johansson, G. \& Winroth, M. (2010). Introducing environmental concern in manufacturing strategies: implications for the decision criteria. Management Research Review 33(9), 877-899.

Ocampo, L. \& Clark, E. (2014). A framework for capturing uncertainty of group decision-making in the context of the AHP/ANP. Advances in Industrial Engineering and Management 3(3), 7-16

Saaty, T. L. (1980). The Analytic Hierarchy Process. New York: McGraw-Hill.

Skinner, W. (1969). Manufacturing-missing link in corporate strategy. Harvard Business Review 47, 136-145.

Tseng, M.L. (2009). A causal and effect decision-making model of service quality expectation using grey-fuzzy DEMATEL approach. Expert Systems with Applications 36(4), 7738-7748. 